\title{
Market-based instruments in South Africa: a review
}

\author{
A. Nahman, L. Godfrey \& R. Wise \\ Council for Scientific and Industrial Research, South Africa
}

\begin{abstract}
Sustainable development presents particular challenges for developing countries, where the need for rapid economic development to overcome poverty and inequality often makes environmental protection a low priority. Market-based instruments (MBIs), which make it possible for environmental considerations to be built into everyday economic decision-making, and for environmental objectives to be achieved at the lowest possible cost to society, may be appropriate policy instruments for addressing these types of challenges. However, despite their potential advantages in the developing country context, MBIs may not always be appropriate for developing countries, and should not be seen as panaceas that can simply be transferred to developing countries without considering local circumstances. By way of example, this paper reviews the use of MBIs for solid waste management in South Africa, and presents results from a survey of waste management authorities regarding the opportunities and constraints associated with their implementation. It is found that a number of fundamentals need to be put in place before MBIs can be implemented. However, this does not imply that the potential of MBIs should be ignored. Indeed, it is proposed that MBIs can be designed and implemented in an innovative, incremental way whereby capacity and experience are gradually developed over time.
\end{abstract}

Keywords: market-based instruments, solid waste management, developing countries, sustainable development, panaceas.

\section{Introduction}

The challenges associated with sustainable development are particularly difficult and complex in developing countries, where trade-offs between economic, social 
and environmental objectives are unavoidable. Given the need for rapid social and economic development to overcome poverty and under-development in most developing countries, decision makers tend to prioritise social and economic development agendas, often at the expense of environmental integrity. A more balanced approach is therefore required, whereby inter- and trans-disciplinary tools, methods and frameworks are used to facilitate the decision-making process (Burns et al [1]). This is particularly important where social, economic and environmental variables are seemingly incommensurate.

Environmental economics is an inter-disciplinary science devoted to the resolution of these types of trade-offs. It is based on the idea that all forms of capital, including social and natural capital, can be valued in economic terms, facilitating the resolution of tradeoffs between economic, social and environmental objectives. In terms of policy, environmental economists advocate market-based approaches to resolving these trade-offs, whereby environmental objectives can be achieved at minimum cost to society, thus easing the economic burden of environmental protection. It provides insight into the impact of incentives on people's decision making; and can then construct incentives to ensure that people's behaviour leads to sustainable outcomes. Environmental economics, and market-based instruments (MBIs) in particular, therefore seem well-suited to addressing the challenges associated with sustainable development. It would thus seem that an environmental economics perspective is particularly important in developing countries; where limited resources, and the need for economic growth and development, imply that cost-effectiveness should be a key criterion for environmental policy.

However, economists have tended to see MBIs as a panacea that can be applied to all environmental problems in all contexts. There has therefore been a tendency for economists to advocate the use of sophisticated, developed country instruments in developing countries, which may not necessarily be ready for them, or which at least require that the context be taken into account (Bell [2], Bell and Russell [3], O'Connor [4], Russell and Vaughan [5], Ostrom et al [6], Brock and Carpenter [7]). An underlying characteristic of this 'panacea thinking' is that "the set of preferences, the possible roles of information, and individual perceptions and reactions are assumed to be the same as those found in developed Western market economies" (Ostrom et al [6]). This is often not the case, resulting in misguided policies that often do more harm than good (Ostrom et al [6], Brock and Carpenter [7]).

The aims of this paper are (1) to assess the opportunities for, and constraints to, the implementation of MBIs in the solid waste sector in South Africa (SA); and (2) to suggest an approach to the implementation of MBIs that takes the developing country context into account. Section 2 introduces the concept of MBIs and reviews MBIs that have been used in the solid waste sector internationally. Section 3 presents the South African context, while Section 4 briefly describes the survey methodology used to assess opportunities for and constraints to the implementation of MBIs in SA. Section 5 presents the results, while Section 6 suggests a possible approach for implementing MBIs in developing countries. 


\section{Market-based instruments in theory and in practice}

Environmental problems have traditionally been addressed using command and control (CAC) regulations, which regulate behaviour directly by prescribing specific legislation and standards which must be achieved, and enforcing compliance through the use of penalties and fines (Perman et al [8]). In developing countries, including SA, CAC mechanisms still dominate environmental policy (Pearce and Turner [9], National Treasury [10]).

By contrast, MBIs, such as environmental taxes and subsidies, seek to change behaviour indirectly; by changing relative prices (and hence incentives) that individuals and businesses face. These instruments have grown in importance in developed countries since the 1980s; and there has also been growing interest in some developing countries in the use of such instruments (Bell and Russell [3], Pearce and Turner [9], Inter-American Development Bank [11]).

Various types of MBIs can be used in the field of solid waste management (SWM). These include product and input taxes, deposit-refund schemes, and quantity-based user charges.

Product and input taxes aim to reduce waste generation by increasing the price of environmentally significant products and inputs; thereby decreasing demand or making alternative products or inputs more attractive. Internationally, they have been applied to tyres, motor vehicles, batteries (particularly car batteries), non-recyclable containers (plastic, glass, metal and paper; particularly non-returnable beverage containers), non-biodegradable plastic bags, lubricant oils, and fuels (Forum for Economics and the Environment [12], United Nations Environment Program [13]). They are generally applied at a national level.

Deposit-refund schemes essentially combine a product tax (the 'deposit') and a subsidy ('refund'). The deposit is paid upon purchase and is refunded upon return of the used product or packaging for recycling or re-use, thereby providing an incentive to return recyclable or reusable items rather than throw them away (Forum for Economics and the Environment [12], Pearce and Turner [14]). They are most commonly used for beverage containers, although they have also been used for tyres, batteries, and even cars (e.g. in Sweden and Norway) (Inter-American Development Bank [11]). They are generally applied at a local level.

Finally, quantity-based user charges for collection or disposal aim to provide an incentive to reduce waste generation or disposal at the margin, or to divert waste from landfill to recycling or re-use. For example, charges for municipal waste collection services can be based on the volume or weight of waste collected. Quantity-based collection charges have been used by some municipalities in Switzerland (and some other European countries), South Korea, the United States and Canada (Inter-American Development Bank [11], Pearce and Turner [14], Reschovsky and Stone [15], Choe and Fraser [16]). Variable landfill fees (based on weight) are also common, although these generally fail to affect the incentives of waste generators themselves and therefore have little influence on the quantity of waste generated. Quantity-based charging is usually applied at the municipal level. 
MBIs appear to have some important advantages over CAC in the developing country context, including cost effectiveness; promotion of economic efficiency; incentives for innovation; the potential for self-regulation; and the potential for revenue generation, which can be used to finance environmental expenditures or to reduce distortionary taxes elsewhere in the economy, such as on labour, thereby generating a 'double dividend' (National Treasury [10]).

Nevertheless, MBIs require the fulfilment of a number of pre-conditions. Firstly, they require "reasonably well functioning markets with adequately defined property rights, the presence of private enterprise motivated to reduce costs, some degree of competition, competent judicial systems, and limited price distortions" (Inter-American Development Bank [11]). Developing countries are generally characterised by poorly functioning markets and/or market failure, whereby these conditions fail to hold.

Secondly, MBIs can be administratively demanding on government at all levels, and require sufficient institutional capacity in terms of acquiring relevant management information, monitoring compliance and illegal activities, and enforcement (United Nations Environment Program [13]). Many developing countries lack the necessary institutional capacity (Bell and Russell [3], Russell and Vaughan [5]). Thus, institutional capacity building is an important precursor to the implementation of MBIs (Pearce and Turner [14]).

Finally, there must be political will to address environmental problems as a priority issue, particularly given the likelihood that many MBIs (particularly taxes and charges, which may impact negatively on competitiveness and equity) will be politically unpopular. However, there are various ways of alleviating the negative impacts associated with taxes so as to ensure that the overall impact of the tax is neutral; such as tax shifting, revenue recycling and transfer payments.

\section{The South African context}

There are few MBIs in SA with explicit environmental objectives. Although taxes and charges exist in the transport, energy, water and waste management sectors, these are largely intended for cost-recovery or revenue-raising purposes, with any environmental outcomes being achieved only incidentally (National Treasury [10]). Currently, the only product tax in SA with explicit environmental objectives is the plastic bag levy, although there is also a proposed levy on tyres and potential for the expansion of product taxes to such items as packaging, batteries, and electronic equipment (National Treasury [10]). There are also a number of locally operated deposit-refund schemes in SA, relating largely to glass and plastic beverage containers. Again, these can potentially be expanded to include other products (National Treasury [10]).

Charging for waste collection in SA varies widely between municipalities, with some municipalities funding waste collection services entirely through property taxes, and others almost entirely through user charges, and still others using some combination thereof. In the case of user charges, some are based on plot size or property value, while others are based on the frequency of collection or number of containers collected (National Treasury [10]). 


\section{Methodology}

Face-to-face and telephonic semi-structured (questionnaire-based) interviews were conducted with 18 individuals from 15 municipalities and private waste management companies across SA between October and December 2007. Discussions were also held with representatives of the National Treasury, although this paper confines itself to the results of the discussions with local authorities. Copies of a summary report on MBIs for SWM, as well as the survey questionnaire, were distributed prior to the interviews. Interviewees were encouraged to read the report and begin responding to the questionnaire prior to the interview. During the interview itself, interviewees were presented with a brief summary of MBIs and the issues involved, after which semi-structured discussions were held based on the questionnaire. Interviewees were also encouraged to raise other issues not dealt with in the questionnaire. Interviewees were then asked to complete the questionnaire in their own time if necessary, and to provide information regarding their waste collection tariffs and landfill tipping fees (where applicable).

\section{Results}

Respondents were first asked questions regarding their current waste management charging practices. Most $(80 \%)$ of the municipalities and companies in the sample claimed to have some form of variable or quantitybased tariff structure, with two municipalities using fixed rates and one not charging for waste collection at all. However, of those claiming to use variable or quantity-based charges, only in one case are charges based on the actual weight or volume of waste collected. In all other cases, charges are based on the number of containers collected. The problem is that, in most cases, the unit by which waste generators are charged is one 240 litre 'wheelie' bin, or between two and four 85 litre bins or bags, or part thereof. These large units fail to encourage waste minimisation, as waste generators are charged the same amount irrespective of how full the bins are, or of how many bags (within the prescribed limit) are collected; such that there is still no incentive to reduce waste generation at the margin (Fullerton and Walls [17]). Only in two cases are charges based on a unit of one $85 \mathrm{~L}$ bin, which is clearly preferable to charges based on larger units; although, again, charges are the same irrespective of how full the bin is. There have been some proposals to move toward a weight-based charging system, although such a system requires fairly sophisticated equipment and monitoring capabilities. Furthermore, quantity-based user charges are likely to lead to an increase in illegal dumping as a means of avoiding the fees.

Sixty-six percent of municipalities and companies in the sample have landfill tipping fees based either on weight (where a weighbridge is available) or volume. Again, however, the units involved tend to be large (such as per tonne of waste, or based on vehicle size). Furthermore, marginal disposal costs are not generally passed on to waste generators in the form of marginal waste collection costs, such that, again, little incentive for waste minimisation is created. 
Furthermore, the true costs of landfilling (including externalities, e.g. health, social and environmental costs) are not currently built into landfill tipping fees in SA. Indeed, none of the municipalities interviewed claimed to cover external costs in their waste collection or disposal fees, although one claimed to be looking into this issue. The result is an artificially low cost of landfilling, which makes recycling an unattractive alternative. Thus, correct pricing of landfilling (increasing landfill fees to reflect the full costs associated with this activity) is an important priority. However, as is the case with quantity-based collection fees, increasing landfill tipping fees is likely to lead to an increase in illegal dumping. Thus, as mentioned by several respondents, changing social attitudes regarding appropriate waste management behaviour, through education and awareness programmes, is an important precursor to the implementation of MBIs.

Respondents were then asked questions regarding the opportunities and constraints associated with implementing MBIs for SWM in SA. Seventeen out of the 18 individuals (94\%) felt that MBIs should be implemented in the field of SWM in SA, with only one respondent unsure. However, opinion varied as to the time frame over which they should be implemented. Eleven respondents (61\%) felt that at least some MBIs, or some aspects of MBIs, could be implemented over the short term (0-5 years), with only 6 respondents (33\%) arguing that MBIs should only be implemented in the medium term (5-10 years); and only one respondent arguing that they should only be implemented in the long term (over 10 years). Twenty two percent of respondents argued that different MBIs, or different aspects of MBIs, should be implemented over different time frames.

Respondents saw a variety of opportunities in implementing MBIs. All respondents thought that MBIs could be effective in achieving some reduction in waste generation or in diverting waste from landfill to recycling. However, only six respondents (33\%) thought that MBIs should be implemented with the sole purpose of achieving these outcomes. Two saw income generation as an important secondary benefit; while 8 respondents (44\%) saw the two outcomes (changing behaviour and generating income) as equally important. Only one respondent thought that income generation should be the main purpose of MBIs.

Other opportunities mentioned by respondents included the potential of MBIs to reduce the need for landfill space and prolong the lifespan of landfill sites; their potential to stabilise prices of recyclables and thus stimulate and stabilise viable and sustainable markets for recyclables; the socio-economic benefits associated with recycling, such as local economic development and the creation of job opportunities in the recycling market; improved environmental awareness; skills and technology development; the potential to encourage private investment; and the potential efficiency gains associated with municipal waste management departments being run more like businesses.

However, a large number of obstacles to the implementation of MBIs for SWM in SA were mentioned by respondents (Table 1). Only seven respondents (39\%) felt that MBIs could be easily integrated within the current SA policy framework, while three were unsure. Eight respondents (44\%) felt that MBIs may not be easily integrated into the current policy framework, although half of these mentioned that this would change when the new Waste Management Bill is enacted. According to 
these latter respondents, MBIs could be added as regulations within the framework provided by the Bill.

Table 1: $\quad$ Obstacles to implementation of MBIs for SWM in SA.

\begin{tabular}{|l|c|c|l|l|}
\hline \multicolumn{1}{|c|}{ Question } & Yes & No & Unsure & \multicolumn{1}{|c|}{ Other } \\
\hline $\begin{array}{l}\text { Can MBIs be easily integrated into the } \\
\text { SA policy framework? }\end{array}$ & $39 \%$ & $22 \%$ & $17 \%$ & $\begin{array}{l}\text { When Waste Bill is } \\
\text { enacted 22\% }\end{array}$ \\
\hline $\begin{array}{l}\text { Is SWM seen as being of sufficient } \\
\text { priority for implementation of MBIs? }\end{array}$ & $22 \%$ & $61 \%$ & $0 \%$ & $\begin{array}{l}\text { Not yet but starting } \\
\text { to become so } 17 \%\end{array}$ \\
\hline $\begin{array}{l}\text { Does government have the necessary } \\
\text { enforcement capacity for MBIs? }\end{array}$ & $6 \%$ & $83 \%$ & $6 \%$ & $\begin{array}{l}\text { When Waste Bill is } \\
\text { enacted 6\% }\end{array}$ \\
\hline $\begin{array}{l}\text { Does your organisation or } \\
\text { municipality have the required } \\
\text { capacity for MBIs? }\end{array}$ & $22 \%$ & $50 \%$ & $11 \%$ & $\begin{array}{l}\text { Not yet but can be } \\
\text { developed } 17 \%\end{array}$ \\
\hline
\end{tabular}

Furthermore, 11 respondents $(61 \%)$ believe that waste management is not seen as enough of a priority, either at local or national government level, to enable implementation of MBIs. Four respondents specifically mentioned lack of political will as an important obstacle to their implementation. Likewise, seven respondents (39\%) cited lack of waste education and awareness among the public as an obstacle. Thirteen respondents (72\%) mentioned raising awareness and changing mindsets, e.g. through environmental and waste education or advertising campaigns, as a fundamental precursor to the implementation of MBIs, or as being a necessary complement to the implementation of MBIs, or even as being a key instrument for changing behaviour in its own right.

Another important obstacle mentioned by nearly all respondents was the lack of administrative and enforcement capacity at all levels of government. Only one respondent felt that national government had the necessary enforcement capacity to implement MBIs at the national level in SA, with another respondent unsure. The vast majority ( $89 \%)$, however, doubted the existence of sufficient capacity at national level. Of these, one respondent argued that an enabling environment for such enforcement would be created once the Waste Management Bill is enacted.

Similarly, 12 respondents $(67 \%)$ felt that there was a lack of capacity within their municipalities or organisations for the implementation of MBIs at the local level (responses to this question did not vary significantly between municipalities and private companies). Of these, three (all municipalities) claimed that such capacity could be developed, although this would require an increase in funding and/or staffing. Four respondents claimed that such capacity already existed in their municipalities or organisations, while two were unsure.

Respondents also mentioned the need to create an enabling environment (e.g. provision of bags and drop-off centres, or even kerbside pickup, for recyclables); the difficulty of monitoring waste generators due to the lack of waste licensing and data (e.g. due to lack of a waste information system); low prices of recyclables, which makes use of virgin materials more attractive; the lack of uniformity and stability in the prices of recyclables (and hence in the market for recyclables); the costs associated with transport, monitoring and enforcement; 
lack of access to basic waste services; the negative impacts of further taxes on the poor and on business, and thus the likelihood of resistance from communities and business; other difficulties associated with the enforcement of new policies; lack of staff (particularly skilled staff), funding, vehicles, and other necessary resources; the budgeting process, which makes it difficult for municipal waste management departments to re-invest income into improved SWM; the complicated nature of these instruments, especially in light of the current inability of many municipalities even to deal with basic billing and cost recovery issues (for example, only $43 \%$ of municipalities in the sample who charge for waste collection are able to cover the full operational costs of waste collection services through these charges); and lack of the necessary enabling legislation and legal framework (at least until the Waste Management Bill is enacted).

A number of potential problems were mentioned with regard to specific instruments. In the case of taxes and charges, concerns were raised regarding the impact of taxes or charges on (and thus resistance from) poor communities and businesses; and as to how revenues will be used (e.g. the case of the plastic bag levy, revenues from which are not properly channelled toward the stated purpose of stimulating recycling). In the case of quantity-based charges specifically, concerns were raised regarding possible incentives for illegal dumping created by such charges; the additional data requirements, complexities and costs associated with monitoring and billing (adequate waste data and monitoring/billing capacity are already severely lacking); and regarding the need to change the mindset that waste services should be free.

\section{Summary and conclusions}

In general, almost all respondents felt that MBIs could lead to reduced waste generation and increased diversion of waste from landfill to recycling, and that they should eventually be implemented in the field of SWM in SA, although opinions varied as to the appropriate timeframe for implementation. The general consensus was that a number of fundamentals had to be in place first, including:

- $\quad$ enactment of the Waste Management Bill, which will create an enabling environment for enforcement and provide a framework within which MBIs can be implemented;

- $\quad$ political will (government must see waste management as a priority);

- $\quad$ education and awareness (waste management must be seen as a priority among business and communities; to encourage waste minimisation and recycling, reduce illegal dumping, and promote acceptance of MBIs);

- development of capacity at all levels of government (for administration, monitoring and enforcement of instruments, and billing for services);

- increased access to resources for waste management departments (to develop capacity, recover costs, and improve SWM services);

- correct pricing of landfilling, such that external costs are accounted for;

- $\quad$ waste licensing and data (e.g. through a waste information system); and

- infrastructure for extension of basic waste services, improvement in existing services, and to enhance the convenience of recycling. 
Thus, it may not be appropriate to push for sophisticated MBIs before these fundamentals are in place. However, an existing lack of institutional capacity should not be taken to imply that there is no place for MBIs in developing countries. Instead, institutional limitations must be taken into account in the selection, design and implementation of such instruments.

For example, some instruments may be simpler to implement and administer than others. In this study, respondents indicated concern regarding the lack of monitoring and enforcement capacity at municipal level, especially for the billing of waste services and the monitoring of illegal dumping in the case of quantity-based user charges. This implies that simpler instruments that are more easily enforced and that don't create perverse incentives, such as product taxes and deposit-refund schemes, should be preferred over quantity-based charges.

Furthermore, an existing lack of institutional capacity can be taken into account in the design and implementation of instruments. Policy can be designed in such a way that instruments are implemented incrementally, beginning with relatively simply instruments and becoming increasingly sophisticated as institutional capacity grows (Bell and Russell [3], Russell and Vaughan [5], Pearce and Turner [9]). It is also important to develop a culture of compliance whereby compliance becomes the norm and illegal dumping becomes socially unacceptable (Russell and Vaughan [5]). For example, to start with, it is likely to be easier to place a tax on products at the point of sale, or to monitor waste entering landfill sites or generated by large producers; rather than attempting to monitor the quantity of waste generated by individual households, as well as illegal dumping. It may also be possible to implement deposit-refund schemes, or expand existing schemes to cover other types of products (Bell and Russell [3]). However, as monitoring capacity and a culture of compliance develops, it will eventually become easier to monitor household waste generation, while (ideally) avoiding having to deal with illegal dumping. Further research is therefore required regarding the design of instruments that take developing country circumstances into account and that can develop over time as capacity grows.

\section{References}

[1] Burns, M., Audouin, M. and Weaver, A., Advancing sustainability science in South Africa. South African Journal of Science, 102, pp. 1-6, 2006.

[2] Bell, R.G., Choosing environmental policy instruments in the real world. CCNM/GF/SD/ENV(2003)10/FINAL. Paris. Organisation for economic cooperation and development, 2003.

[3] Bell, R.G. and Russell, C., Environmental policy for developing countries. Issues in Science and Technology, 18(3), pp. 63-70, 2002.

[4] O'Connor, D., Applying economic instruments in developing countries: From theory to implementation. Environment and Development Economics, 4, pp. 91-110, 1998.

[5] Russell, C.S. and Vaughan, W.J., The Choice of Pollution Control Policy Instruments in Developing Countries: Arguments, Evidence and 
Suggestions. International Yearbook of Environmental and Resource Economics, VII ed., Edward Elgar: Cheltenham, U.K., 2003.

[6] Ostrom, E., Janssen, M.A. and Anderies, J.M., Going beyond panaceas. Proceedings of the National Academy of Sciences, USA, 104(39), pp. 15176-15178, 2007.

[7] Brock, W.A. and Carpenter, S.R., Panaceas and diversification of environmental policy. Proceedings of the National Academy of Sciences, 104, pp. 15206-15211, 2007.

[8] Perman, R., Ma, Y., McGilvray, J. and Common, M., Natural resource and environmental economics, Pearson Education: Harlow, 2003.

[9] Pearce, D. and Turner, R.K., Economics and solid waste management in the developing world. CSERGE working paper WM 1994-05. Centre for Social and Economic Research on the Global Environment, 1994.

[10] National Treasury, A framework for considering market-based instruments to support environmental fiscal reform in South Africa. Pretoria. National Treasury, 2006.

[11] Inter-American Development Bank, Economic instruments for solid waste management: global review and applications for Latin America and the Caribbean. Washington, D.C. Inter-American Development Bank, 2003.

[12] Forum for Economics and the Environment, Training manual for the Forum for Economics and the Environment. http://www.econ4env.co.za/ training/training.html 2002.

[13] United Nations Environment Program, Solid waste management. http://www.unep.or.jp/ietc/Publications/spc/Solid_Waste_Management/ind ex.asp. 2005.

[14] Pearce, D. and Turner, R.K., Market-based approaches to solid waste management. Resources, Conservation and Recycling, 8, pp. 63-90, 1993.

[15] Reschovsky, J.D. and Stone, S.E., Market incentives to encourage household waste recycling: Paying for what you throw away. Journal of Policy Analysis and Management, 13(1), pp. 120-139, 1994.

[16] Choe, C. and Fraser, I., The economics of household waste management: A review. The Australian Journal of Agricultural and Resource Economics, 42(3), pp. 269-302, 1998.

[17] Fullerton, D. and Walls, M., Trash Talk. RFF Weekly Policy Commentary, http://www.rff.org/rff/News/Weekly_Policy_Commentary/11_30_07_ FullertonWalls_Commentary.cfm 2007.

[18] Coetzee, B. Personal Communication, City of Cape Town: Solid Waste Management Department, Cape Town, 2007.

[19] Huber, R., Ruitenbeek, J. and Seroa da Motta, R., Market based instruments for environmental policymaking in Latin America and the Caribbean: Lessons from eleven countries. Washington, DC. World Bank, 1997.

[20] O'Connor, D. and Turnham, D., Managing the Environment in Developing Countries. Policy Brief No 2. Paris. OECD Development Centre, 1992.

[21] Organisation for Economic Cooperation and Development, Environmentally related taxes: Issues and strategies. Policy brief. Organisation for economic cooperation and development, 2001. 